\title{
Associations between body condition score at parturition and microRNA profile in colostrum of dairy cows as evaluated by paired mapping programs
}

\author{
C. M. Ylioja, M. M. Rolf, L. K. Mamedova, and B. J. Bradford* \\ Department of Animal Sciences and Industry, Kansas State University, Manhattan 66506
}

\section{ABSTRACT}

MicroRNA (miRNA) are abundant in milk, and likely have regulatory activity involving lactation and immunity. The objective of this study was to determine the miRNA profile in colostrum of overconditioned cows compared with cows of more moderate body condition score (BCS) at calving. Multiparous cows with either high ( $\geq 4.0$ on a scale of 1 to $5 ; \mathrm{n}=7$ ) or moderate BCS ( 2.75 to $3.50 ; \mathrm{n}=9)$ in the week before parturition were selected from a commercial dairy herd. Blood and colostrum were sampled within $24 \mathrm{~h}$ after calving. Blood serum was analyzed for free fatty acid (FFA) concentration. MicroRNA was isolated from colostrum samples after removing milk fat and cells. MicroRNA were sequenced, and reads were mapped to the bovine genome and to the existing database of miRNA at miRBase.org. Two programs, Oasis 2.0 and miRDeep2, were employed in parallel for read alignment, and analysis of miRNA count data was performed using DESeq2. Identification of differentially expressed miRNA from DESeq2 was not affected by the differences in miRNA detected by the 2 mapping programs. Most abundant miRNA included miR-30a, miR-148a, miR-181a, let-7f, miR-26a, miR-21, miR-22, and miR-92a. Large-scale shifts in miRNA profile were not observed; however, colostrum of cows with high BCS contained less miR486, which has been linked with altered glucose metabolism. Colostrum from cows with elevated serum FFA contained less miR-885, which may be connected to hepatic function during the transition period. Potential functions of abundant miRNA suggest involvement in development and maintenance of cellular function in the mammary gland, with the additional possibility of influencing neonatal tissue and immune system development.

Key words: RNA silencing, neonate, transition cow, immune function, bioinformatics

Received March 24, 2019.

Accepted August 3, 2019.

*Corresponding author: bbradfor@ksu.edu

\section{INTRODUCTION}

Timely consumption of colostrum by the dairy calf is crucial for survival, as colostrum conveys immune protection to the calf in the first weeks after birth, when the calf's own adaptive immune system is yet underdeveloped. Literature to date indicates that immunoglobulins present in colostrum are responsible for the bulk of its immunoprotective effect, and the concentration of protein in colostrum, which correlates with IgG content, is used as an indicator of colostrum quality (Bielmann et al., 2010). However, a plethora of other signaling components are present in colostrum, including cytokines, growth factors, immune cells, and exosomal proteins (Hagiwara et al., 2008; Langel et al., 2015; Samuel et al., 2017) that may also contribute to tissue development, provide immune protection, and stimulate maturation of the neonatal immune system.

Noncoding RNA, especially microRNA (miRNA), have been detected in the milk of multiple species, and those miRNA with predicted functions related to immune response are especially abundant in colostrum (Izumi et al., 2012; Chen et al., 2014). Associations between miRNA and extracellular microvesicles such as exosomes or apoptotic bodies, or with Argonaute proteins or HDL particles (Turchinovich et al., 2012), protect against degradation. Milk-derived microvesicles containing miRNA can withstand simulated gastrointestinal conditions (Benmoussa et al., 2016) and be taken up via endocytosis by intestinal cells (Rani et al., 2017) and vascular endothelial cells (Kusuma et al., 2016). From these observations, it is plausible that miRNA in milk may survive gastrointestinal conditions of the calf to regulate function of neonatal tissues. Researchers studying miRNA in milk have often focused on those miRNA contained in exosomes. Although a large fraction of the miRNA in milk may be contained in microvesicles, the ultracentrifugation methods often used for exosome isolation yield only a subset of the miRNA present in the original sample and can result in selection bias of certain miRNA (Benmoussa et al., 2017, 2016). 
MiRNA found in milk may be unique to the mammary gland or may reflect those found in circulation from other tissues or cells (Kosaka et al., 2010). Altered mammary miRNA profile has been associated with both mammary-specific conditions, such as mastitis (Sun et al., 2015), and with less localized treatments, such as dietary changes ( $\mathrm{Li}$ et al., 2015b). It is unknown whether alterations in metabolic phenotype, such as those seen in dairy cows during the transition from gestation to lactation, would also affect the miRNA found in milk.

Dairy cows in the periparturient period exhibit altered immune function (Ingvartsen and Moyes, 2015). Cows with excessive body condition before calving undergo a greater degree of adipose tissue mobilization, have greater circulating free fatty acid (FFA) and ketone concentrations, and are predisposed to fatty liver and metabolic disease after calving (Sordillo and Raphael, 2013). These cows also display greater systemic inflammation as well as a suppressed immune response (Sordillo et al., 2009). In humans, obesity is associated with an altered profile of circulating miRNA (Manning et al., 2019), and differentially expressed miRNA have been associated with diabetes and metabolic syndrome (Karolina et al., 2012; De Candia et al., 2017), which have characteristics in common with periparturient dairy cows.

Our first objective was to identify the miRNA most abundant in colostrum; this has been done by other groups, but sample size has been small or samples have been pooled before sequencing (Chen et al., 2010; Gu et al., 2012). Additionally, we sought to examine the colostrum miRNA profile of cows divergent in adiposity, classified by either BCS or plasma FFA at the time of calving. We hypothesized that excessive adiposity of the dam would affect the profile of miRNA in colostrum, which could have implications for colostrum supporting the health of the bovine neonate. Our secondary objective was to assess our read-mapping results using a second miRNA read-alignment program. Many programs and pipelines exist for bioinformatic processing of miRNA data, such as those compared by $\mathrm{Li}$ et al. (2012). Programs differ in data processing (sequence mapping, pipeline tools used) as well as allowed user inputs (reference files, customizable settings), which may affect results of read alignment. The miRDeep2 program (https://www.mdc-berlin.de/content/mirdeep2 -documentation) is widely used by researchers analyzing miRNA sequencing data, and Oasis 2.0 (https:// oasis.dzne.de/) is a more recently developed web-based program. These use Bowtie (Langmead et al., 2009) and STAR (Dobin et al., 2013), respectively, for initial alignment of mapped reads. As variation in this step can influence results, we chose to use these 2 programs in parallel for alignment of raw reads, followed by a common method for analysis of mapping results.

\section{MATERIALS AND METHODS}

Multiparous Holstein cows were selected from a commercial dairy herd based on BCS at calving. Body condition of cows in a maternity pen was evaluated weekly; scores reported by 3 trained individuals were averaged. Each cow with BCS of at least 4 (using a 1 to 5 scale; Ferguson et al., 1994) at the time of calving was paired with a cow that exhibited BCS between 2.75 and 3.50, calving within $5 \mathrm{~d}$ of each other. Samples were collected from a total of 16 cows $(n=7$ for high BCS; $n=9$ for moderate BCS) between October and November 2017. Samples from 2 selected high-BCS cows were missed, resulting in the imbalance between groups. Average parity was 3.1 (range: 2 to 5 ).

According to farm protocol, newborn calves were removed from calving pens immediately after birth and fed thawed colostrum previously tested for quality. All fresh cows calving within a 24-h period were milked for initial colostrum collection around $1300 \mathrm{~h}$ daily. Colostrum was collected using an automated milking system (Astronaut A3, Lely Ltd., Maassluis, the Netherlands). Blood was also collected from each cow via coccygeal venipuncture into 10-mL Vacutainer serum tubes (Becton Dickinson and Co., Franklin Lakes, NJ) for analysis of circulating fatty acids. Colostrum samples were tested using a Brix refractometer to estimate IgG content at the time of sample collection. All methods were approved by the Kansas State University Institutional Animal Care and Use Committee (protocol \#3807).

\section{Sample Processing and Analysis}

Blood samples were allowed to clot at $4^{\circ} \mathrm{C}$ before centrifugation $\left(2,800 \times g\right.$ at $20^{\circ} \mathrm{C}$ for $\left.15 \mathrm{~min}\right)$; serum was removed and stored at $-20^{\circ} \mathrm{C}$ until FFA analysis (NEFA-HR; Wako Chemicals USA Inc., Richmond, VA) was conducted. Colostrum was collected into a 50$\mathrm{mL}$ sterile vial and kept on ice during transport $(<3 \mathrm{~h})$ to the laboratory for processing. Phenylmethylsulfonyl fluoride $(100 \mu M)$ was added to inhibit proteolysis. Colostrum was centrifuged $\left(4,000 \times g\right.$ at $4^{\circ} \mathrm{C}$ for $\left.30 \mathrm{~min}\right)$; milk fat was removed and the cell pellet discarded (modified from Blans et al., 2017). The aqueous supernatant was then diluted 1:1 with sterile Dulbecco's PBS (Gibco, Grand Island, NY) to reduce viscosity and centrifuged again at $4,000 \times g$ at $4^{\circ} \mathrm{C}$ for 20 min to pellet residual cells. Supernatant was again removed and stored at $-80^{\circ} \mathrm{C}$ until RNA isolation.

RNA was isolated using the miRNeasy kit for serum and plasma (Qiagen, Hilden, Germany). This kit has 
A

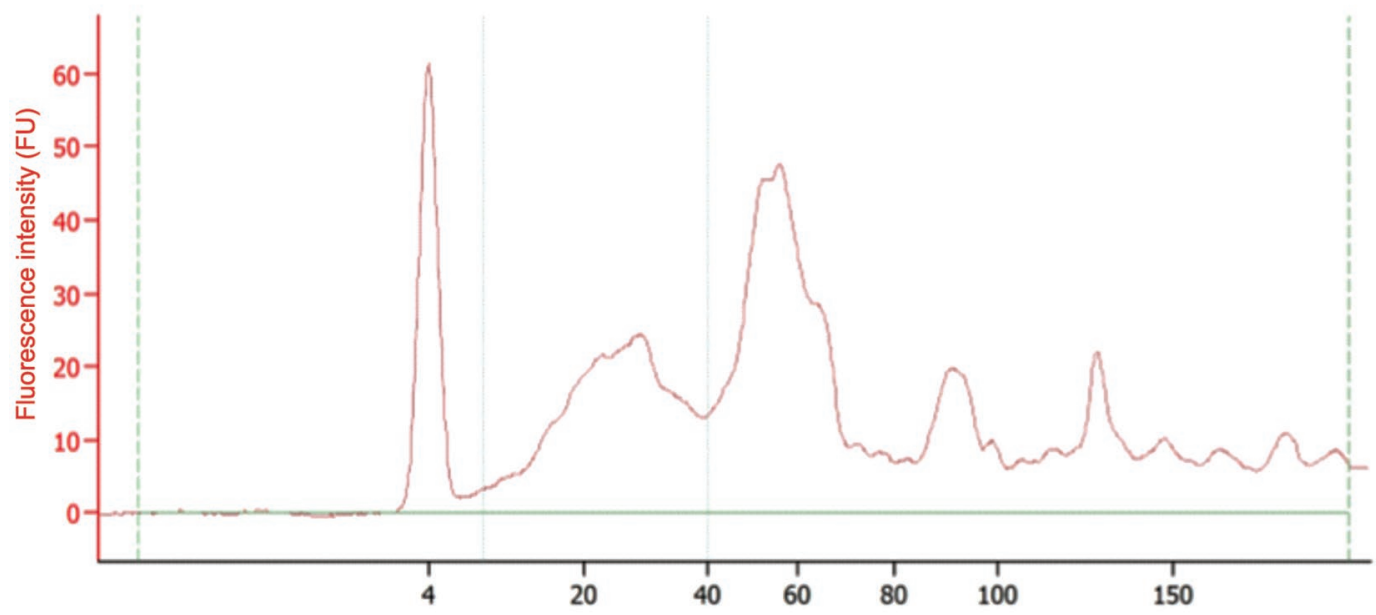

B

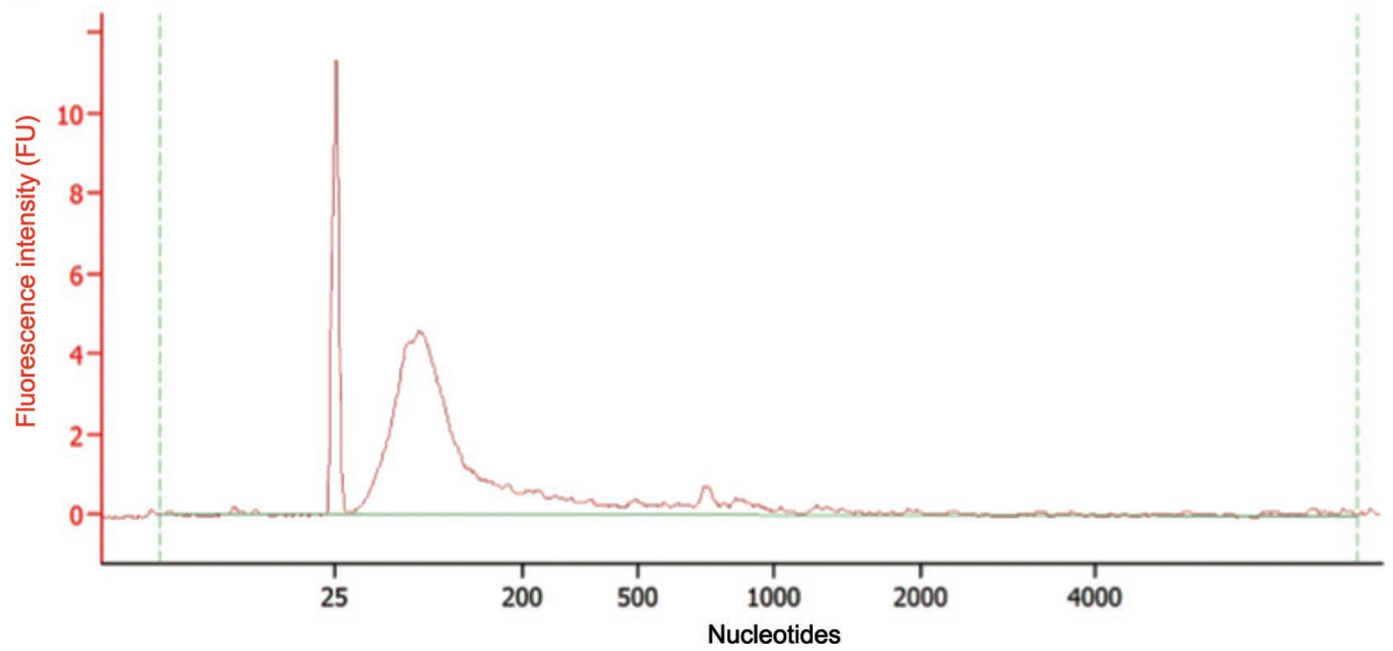

Figure 1. The RNA extracted from de-fatted colostrum was analyzed for size distribution before sequencing. Representative length distribution of RNA is shown plotted against fluorescence intensity, derived from (A) Bioanalyzer Small RNA chip, and (B) Bioanalyzer Total RNA Nano chip (Agilent Technologies, Santa Clara, CA). FU = fluorescence units. RNA integrity number (RIN) values were not measurable for our samples, as the ribosomal RNA used in calculating this value is contained largely in the cells and cytoplasmic crescents in milk, which were removed before RNA isolation.

been widely used in other milk miRNA and milk exosome miRNA studies and successfully isolates miRNA from exosomes as well as from supernatant (Izumi et al., 2015). Qiazol $(1000 \mu \mathrm{L})$ was added to $200 \mu \mathrm{L}$ of diluted colostrum, and isolation was performed according to kit protocol. Samples were eluted into $30 \mu \mathrm{L}$ of elution buffer and assessed for concentration and 260/280 absorbance ratio using a Take3 microvolume plate (Biotek Instruments, Inc., Winooski, VT) and SynergyHTX plate reader (Biotek Instruments, Inc.); 260/280 ratios of isolated RNA averaged $1.83 \pm 0.09$. Concentrations of RNA ranged from 20 to $94 \mathrm{ng} / \mu \mathrm{L}$ and averaged $49 \pm$ $22 \mathrm{ng} / \mu \mathrm{L}$. Samples were also analyzed with an Agilent 2100 Bioanalyzer (Agilent Technologies, Santa Clara, CA) using both RNA 6000 Nano (catalog no. 5067-
1511) and Small RNA (catalog no. 5067-1548) chips to assess concentration and oligonucleotide size profile. Representative size spectra obtained from Bioanalyzer data with Total RNA Nano chips and Small RNA chips are shown in Figure 1.

Samples of isolated RNA were submitted to the University of Kansas Medical Center's Genome Sequencing Facility (Lawrence, KS) for library preparation and sequencing. Sample libraries were prepared using the TruSeq Small RNA sample prep kit (Illumina, Hayward, CA) and sequenced on a HiSeq 2500 (Illumina) using a 2-lane flow cell. Samples were run as single reads with 65-cycle read length, and produced on average $5.87( \pm 0.49)$ million reads per sample. 


\section{Data Processing and Statistical Analysis}

Cutadapt (v. 1.16; https://cutadapt.readthedocs .org/) was used for quality trimming, with a quality value threshold of 15 on the $5^{\prime}$ end and 10 on the $3^{\prime}$ end, before trimming $3^{\prime}$ adapters. Quality was assessed before and after trimming with FastQC (www .bioinformatics.babraham.ac.uk/projects/fastqc/). The bovine genome ARS-UCD1.2 (https://www.ncbi.nlm .nih.gov/assembly/GCF_002263795.1/) was indexed with Bowtie (v. 1.2.2; http://bowtie-bio.sourceforge .net) before mapping reads with the mapper script of the miRDeep2 program (Friedländer et al., 2012; v. 2.0.0.8), allowing read lengths greater than 17 nucleotides and with a maximum of 50 mapping positions in the genome (options -l 18 -r 50). The miRDeep2 script was used to match mapped reads to known miRNA in the miRBase database (Kozomara and Griffiths-Jones, 2014 ; v. 22 ; mirbase.org/ftp), and to predict novel miRNA using additional known miRNA from human and mouse species.

Output files of miRNA counts were analyzed for differential expression using the Bioconductor package DESeq2 (Love et al., 2014; R v. 3.5.1; DESeq2 v. 1.20.0). A total of 509 miRNA were detected. After removal of those with 10 or fewer total reads across all samples, 343 miRNA remained for analysis. Read counts were analyzed for effects of BCS, FFA, and time elapsed between calving and colostrum collection. Analysis of BCS as either a descriptive (high vs. moderate group) or continuous variable produced identical results. Overall effects of BCS and FFA were analyzed, controlling for differences due to collection time. Differentially expressed (DE) miRNA were those with a false discovery rate (FDR)-adjusted $P$-value $<0.1$.

Raw fastq files were also uploaded to the sRNA Detection module of Oasis 2.0 (Rahman et al., 2018; https://oasis.dzne.de/) to validate mapping results. According to the program pipeline, reads were trimmed for quality and 3' adapters (cutadapt v. 1.7.1, https:/ /cutadapt.readthedocs.org/; FastQC v. 0.10.1, http:// www.bioinformatics.babraham.ac.uk/projects/fastqc/) before mapping to known bovine miRNA in miRBase (v. 21) using STAR (Dobin et al., 2013; v. 2.4.1d). Only reads between 15 and 50 nucleotides were used, mismatches were allowed at $5 \%$ of total read length, and reads mapping to more than 5 locations in the genome were discarded. Oasis used miRDeep2 (v. 2.0.0.5) to map reads to the bovine genome (assembly UMD 3.1) for prediction of novel miRNA. A total of 779 known miRNA were detected, and after filtering out those with 10 or fewer total counts across all samples, 457 miRNA were analyzed for differential expression using DESeq2, as described earlier.
To test for variables that could potentially confound the effect of BCS group, statistical analysis of the effect of BCS group on serum FFA, BCS, Brix values, and time elapsed between parturition and colostrum collection were conducted using the mixed procedure of SAS (version 9.4, SAS Institute Inc., Cary, NC). Effect of collection time on Brix values was also assessed.

\section{RESULTS AND DISCUSSION}

\section{MicroRNA Identification}

Using the mapper script of miRDeep2, $3.3( \pm 0.34)$ million reads successfully mapped to the bovine genome, and 899,705 (range: 460,561 to $1,939,191$ ) reads mapped to existing bovine miRNA in the database at mirbase.org. In comparison, Oasis 2.0 identified $1,547,114($ range $=984,337$ to $2,567,670)$ miRNA reads mapping to previously identified miRNA in the bovine genome. Upon closer inspection, many of these miRNA were categorized as predicted miRNA, defined as novel miRNA previously detected by Oasis and contained in their internal database but not yet incorporated into miRBase (Rahman et al., 2018). Although information on predicted sequence and structure are available through the Oasis search function, it is difficult to draw meaningful conclusions regarding the validity and potential functions of these predicted miRNA. For instance, Oasis mapping reported p-bta-miR-20 (note: unique nomenclature; not the same as miR-20) to be the most abundant miRNA detected, but submission of the mature sequence to NCBI's BLAST function resulted in only partial matches to multiple predicted (but uncharacterized) noncoding RNA species.

Disregarding these predicted miRNA, the number of detected miRNA was similar between miRDeep2 and Oasis mapping, which use Bowtie and STAR alignment software, respectively. Some differences were apparent regarding rank of miRNA in order of abundance and also regarding identification of miRNA. For instance, miR-3600 was detected by Oasis but not by miRDeep2, whereas miR-26a, miR-22-3p, and let-7b were only detected by miRDeep2 (Figure 2). Examination of the miR-3600 sequence with NCBI's BLAST function revealed an identical sequence for miR-3600 and miR-22-3p, which may partially explain mapping differences. However, Oasis detected 7,243 reads mapping to miR-3600, whereas miRDeep2 detected 28,610 reads for miR-22-3p, leaving room for other sources of mapping variation as well. Oasis also detected triple the number of miR-200b reads compared with miRDeep2. This miRNA has high similarity with sequences of miR-200c and miR-429, but neither had enough read counts with miRDeep2 mapping to be able to entirely 

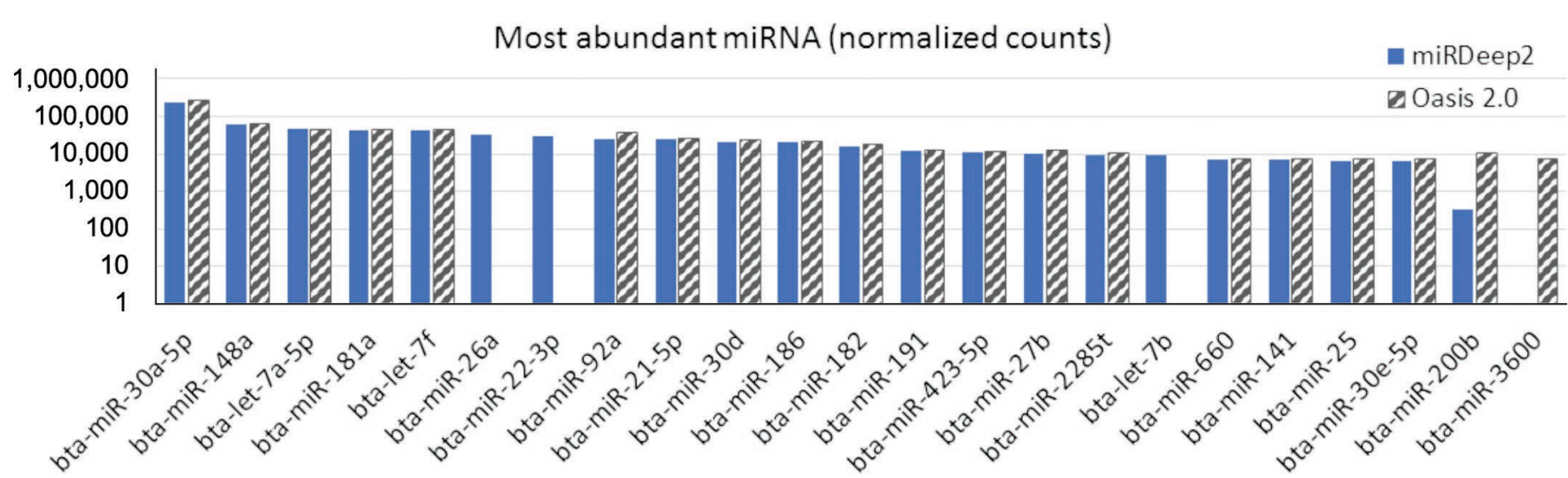

Figure 2. Most abundant microRNA (miRNA) in colostrum, with comparison between miRDeep2 (solid blue bars) and Oasis 2.0 (striped gray bars) results. RNA was isolated from colostrum; raw reads from small RNA sequencing were aligned to the bovine genome and the database of known miRNA using either miRDeep2 (https://www.mdc-berlin.de/content/mirdeep2-documentation) or Oasis 2.0 (https://oasis.dzne.de/), and analyzed with DESeq2 (Love et al., 2014). The 20 most abundant miRNA for both programs (according to the mean of normalized counts of all samples) are shown here. Note the log scale on the y-axis; the top 10 most abundant miRNA accounted for 71 and $74 \%$ of all reads, according to miRDeep2 and Oasis 2.0 mapping, respectively. The most abundant miRNA alone, miR-30a-5p, accounted for 30 or $34 \%$ of all reads, according to mapping by miRDeep2 and Oasis 2.0, respectively. MiR-148a accounted for $8 \%$ of all reads. Normalized counts are calculated by DESeq2 by first dividing raw counts for each gene by the geometric mean of that gene across all samples. Of the resulting ratios, the median value within each sample becomes the normalization factor for that sample by which raw counts are divided to produce the normalized counts (Love et al., 2014).

attribute differences to the algorithm settings for handling ambiguous sequences.

In addition to the alignment algorithms used by the 2 programs, discrepancies in miRNA identification between Oasis and miRDeep2 could be due to version differences in the software used, the annotated reference genome used, the database version of known miRNA, or other mapping settings. For miRDeep2 mapping, we used the most recent assembly of the bovine reference genome (ARS-UCD1.2, released April 2018), whereas Oasis 2.0 used UMD 3.1 (released December 2009). Oasis discarded any reads mapping to more than 5 genome locations, but miRDeep2 allowed those mapping up to 50 locations. Oasis and miRDeep2 used the miRNA database versions 21 and 22 , respectively, which were released in 2015 and 2018. To estimate the extent to which these may have contributed to the alignment differences between the programs, we realigned the raw data of 2 of the cows using miRDeep2 but with the settings used by Oasis (3.1 UMD reference genome, miRBase version 21 , and no more than 5 mapping locations). Surprisingly, the resulting miRNA counts were identical to those of our original alignment using miRDeep2, indicating that differences in read alignment between the 2 programs were unaffected by that particular combination of settings.

\section{Effects of Maternal Adiposity}

In this study, we sought to examine whether the miRNA profile of colostrum produced by the dairy cow is associated with measures of adiposity at the time of parturition. As described below, we found very few statistical differences between cows characterized by circulating FFA or by BCS, regardless of sequence alignment program used. Nevertheless, examination of the few miRNA that were DE, as well as the miRNA most abundant in colostrum, may shed light on the potential for colostrum components to regulate function at the transcriptional level.

Body Condition Score. In accordance with study design, BCS was significantly different between high and moderate BCS groups (4.12 vs. $3.28, \mathrm{SEM}=0.06$; $P<0.001$; Figure 3a). Time between calving and colostrum collection was $10.0 \pm 6.2 \mathrm{~h}$ (mean $\pm \mathrm{SD}$ ), with no difference between BCS groups (8.0 and 11.6 for high and moderate groups, respectively; $\mathrm{SEM}=2.2$; $P=0.27)$. BCS group was unrelated to Brix values of colostrum (24.9 vs. 24.3 for high and moderate BCS groups, respectively; $\mathrm{SEM}=1.6 ; P=0.82$ ).

Initially, global differences in colostrum miRNA profiles of different cows were assessed by principal component analysis. The 2 derived principal components explained $42 \%$ of the variation across samples; however, samples did not cluster by BCS group (Figure 4). The only DE miRNA for effect of BCS was miR-486, which was less abundant for cows with $\mathrm{BCS} \geq 4.0$, compared with cows with moderate BCS (FDR-adjusted $P=$ 0.06; Figure 5a). Results were irrespective of mapping program used to produce miRNA count data, with similar fold change and $P$-values produced for miR486 (fold change of -2.24 and FDR $P$-value of 0.06 for 
A

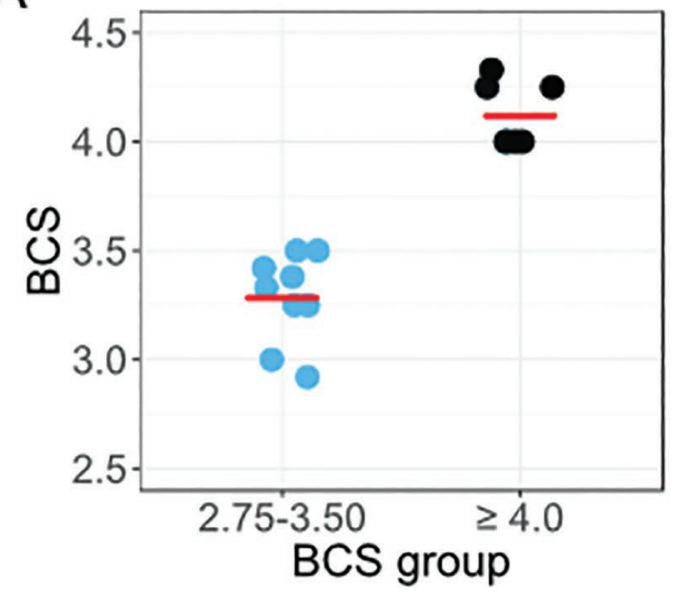

B

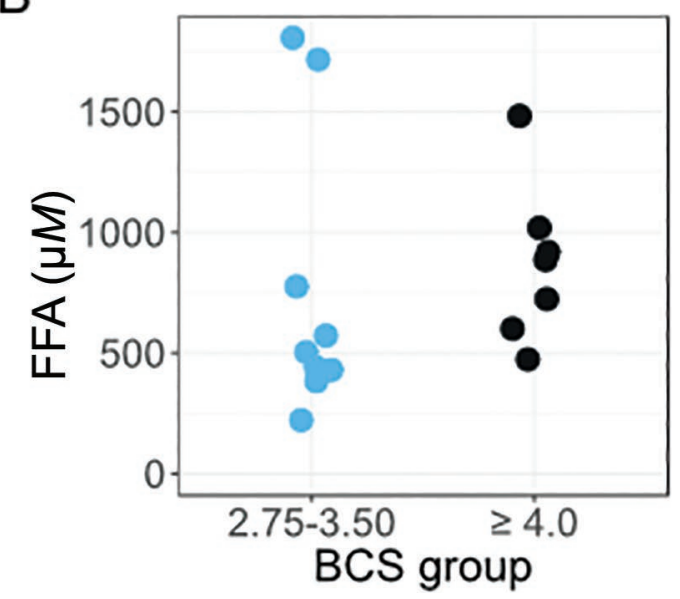

Figure 3. Measures of adiposity and lipolysis at parturition. Cows of either moderate (2.75-3.50) or high ( $\geq 4.0)$ BCS at time of parturition were enrolled. (A) Distribution of BCS at calving by group. Group means (3.28 and 4.12 for moderate- and high-BCS groups, respectively; SEM $=0.06, P<0.001$ ) are shown as horizontal red crossbars. (B) Distribution of serum free fatty acid (FFA) concentration within BCS groups on the day of parturition. Mean FFA did not differ between groups, except when 2 outliers in the moderate-BCS group were excluded.

miRDeep2; fold change of -2.28 and FDR $P=0.07$ for Oasis).

Through its inhibitory effect on phosphatase and tensin homolog (PTEN) protein, miR-486 may play an important role in regulating lactation (Li et al., 2015a). This protein constrains proliferation and differentiation of mammary epithelial cells (MEC) by downregulating the PI3k-Akt pathway in mice (Chen et al., 2012a), and overexpression of PTEN in bovine MEC reduced synthesis of milk components in vitro (Wang et al., 2014). In heifers, elevated BCS has been linked to impaired mammary development and lactation performance (Silva et al., 2002), although the role of mammary miRNA regulation (and miR-486 in particular) has not been evaluated in the context of altered body composition. Additionally, although BCS is reflective of peripheral adipose depots, alterations in the mammary gland also occur in early lactation, such as the regression of mammary adipocytes to allow for epithelial cell growth and milk secretion (Zwick et al., 2018). Alterations of miRNA in either cell type may contribute directly to variation in milk miRNA content; in this case, one study detected miR-486 in bovine mammary epithelium but not in mammary adipose tissue ( $\mathrm{Li}$ et al., 2015a). Adipokines also are important regulators of mammary function (Palin et al., 2017); although no studies have yet specifically evaluated miR-486, altered adipokine production could conceivably be responsible for indirect effects of adiposity on miRNA regulation.

The function of miR-486 may also be tied to glucose metabolism. Circulating miR-486 was upregulated in obese compared with non-obese children, as well as in adults with type 2 diabetes (Cui et al., 2018). In the same study, overexpression of miR-486 increased proliferation of human preadipocytes and increased glucose uptake by $\mathrm{C} 2 \mathrm{C} 12$ myoblast cells in vitro (Cui et al., 2018). Similar to people with type 2 diabetes, periparturient dairy cows also exhibit altered insulin sensitivity during the adaptation to lactation. Observed differences in miR-486 may be related to more pronounced changes to insulin resistance or glucose utilization in overconditioned cows compared with cows of more moderate BCS.

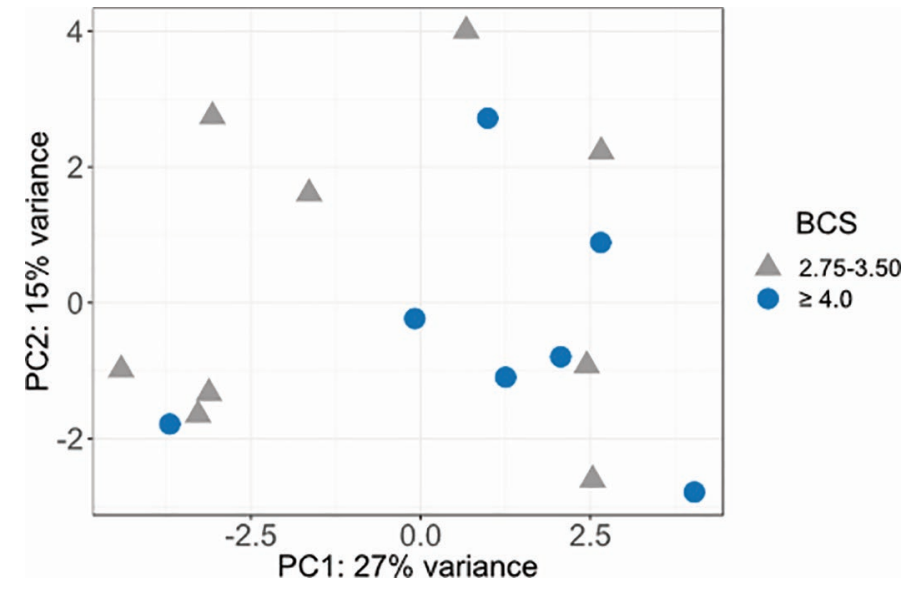

Figure 4. Principal component analysis (PCA) plot of microRNA (miRNA) data, grouped by BCS: gray triangles = moderate BCS, 2.75-3.5; light blue dots = high BCS, $\geq 4.0$. RNA was isolated from colostrum of cows classified by BCS at calving; results of small RNA sequencing were analyzed using DESeq2 (Love et al., 2014). Normalized counts were log-transformed, and values of the first 2 principal components were used to construct the PCA plot. 
Presence of miR-486 in colostrum may have implications for neonate development. Examination of miRNA expression throughout the calf gastrointestinal (GI) tract over the first 6 weeks of life showed both temporal and regional differences in miRNA expression in gut tissue, including that of miR-486 (Liang et al., 2014). Functional analysis by those authors predicted that miR-486 is involved in development of gut epithelium and immune cells. Additionally, studies show that exogenous miRNA can be taken up by intestinal cells in vitro and ex vivo (Arntz et al., 2015; Wolf et al., 2015). It is possible that both the ingested and the endogenously produced forms of miR-486 could have similar effects on GI tissue.

Free Fatty Acids. Similar to BCS, circulating FFA levels have been used to predict the degree of immune suppression exhibited by individual cows in the transition period. Data collected by Tremblay et al. (2018) on d 5 of lactation showed that cows with plasma FFA $>700 \mu M$ exhibited poor metabolic adaptation and greater risk for metabolic disease. One premise for this study was that BCS at parturition could be used to predict subsequent body fat mobilization, which is associated with altered immune function (Lacetera et al., 2005). Because BCS values did not always correlate with analyzed FFA values, we analyzed miRNA data for associations with both BCS and FFA. Circulating FFA concentration did not significantly differ between BCS groups $(P=0.66)$; however, box-and-whisker plots of FFA distribution within each BCS group (using the boxplot procedure of SAS) identified 2 cows in the moderate BCS group as outliers for FFA concentration, with measured FFA values even greater than for those cows in the high BCS group (Figure 3b). Analysis of data after removal of these 2 datapoints confirmed cows with high BCS to have elevated FFA relative to those cows with moderate BCS (873 vs. $476 \mu M$; $\mathrm{SEM}=99$; $P=0.01$; Figure $3 \mathrm{~b}$ ). Plasma FFA concentration was negatively associated with miR-885 abundance in colostrum (Figure 5b). Both mapping approaches revealed a similar association; the calculated fold change was -0.2 per 100- $\mu M$ increase in FFA concentration for both Oasis (FDR $P=0.05)$ and miRDeep2 (FDR $P=0.02$ ).

Previously reported differences in miR-885 abundance point to associations with liver function. Human patients diagnosed with various liver pathologies, including hepatocellular carcinoma, liver cirrhosis, hepatitis B, acute liver injury, or drug toxicity show elevated circulating miR-885 (Gui et al., 2011; Vliegenthart et al., 2015). Individuals confirmed to have fatty liver had elevated mir-885 in circulation, which was also associated with large circulating lipoproteins and expression of oxysterol-binding protein (Raitoharju et al., 2016). Additionally, plasma miR-885 was associated with serum levels of liver enzymes alanine aminotransferase, aspartate aminotransferase, and gamma-glutamyltransferase, which are often used as markers of altered liver function (Raitoharju et al., 2016; Sandrim et al., 2016). Although the available data are largely from human clinical studies, decreased feed intake and increased
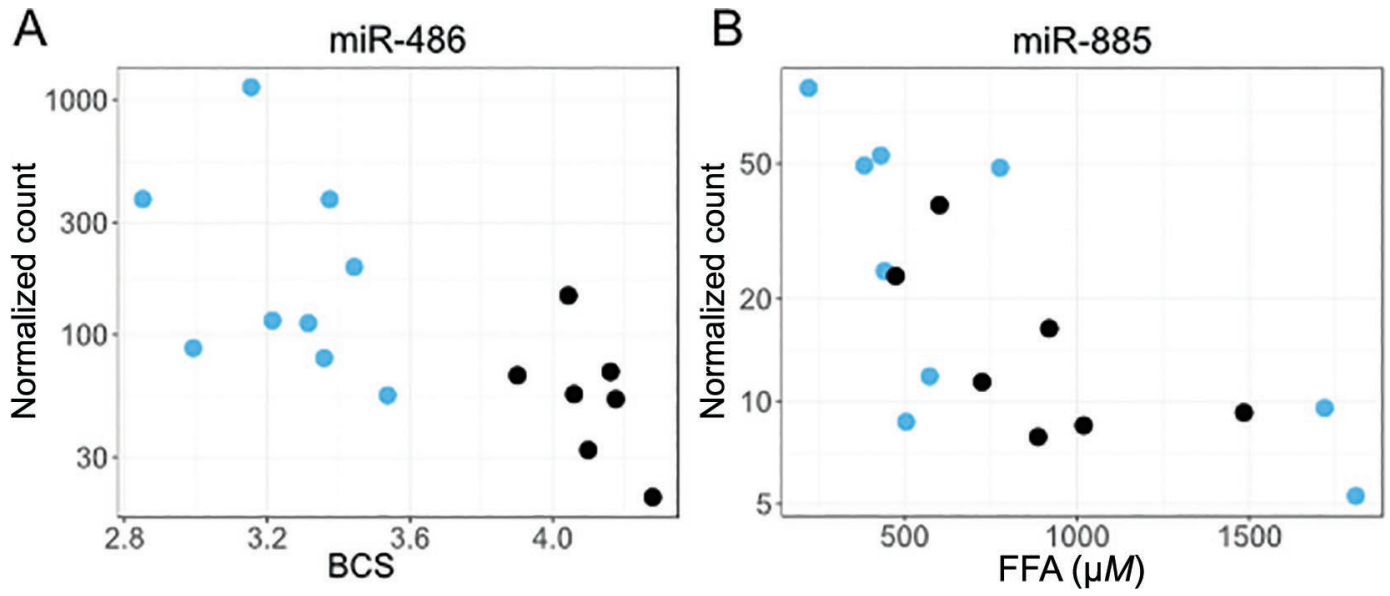

Figure 5. (A) miR-486 was downregulated in cows with BCS $\geq 4.0$ [fold change -2.28 ; false discovery rate (FDR)-adjusted $P=0.07$ ]. (B) miR-885 was downregulated for cows with elevated circulating free fatty acids (FFA; fold change -0.002 per $\mu M$ of plasma FFA; FDR-adjusted $P=0.05)$. RNA from colostrum of cows with moderate $(2.75-3.50$; light blue dots) or high $(\geq 4.0$; black dots) BCS at calving was sequenced and aligned with known microRNA (miRNA) in the bovine genome, using both miRDeep2 (https://www.mdc-berlin.de/content/mirdeep2 -documentation) and Oasis 2.0 (https://oasis.dzne.de/), and analyzed using DESeq2 (Love et al., 2014). Circulating FFA was analyzed as a continuous variable; analysis of both BCS and FFA controlled for differences due to time elapsed before colostrum collection. MicroRNA identified as differentially expressed were similar for both mapping programs. Normalized counts are shown, which are calculated by DESeq2 by first dividing raw counts for each gene by the geometric mean of that gene across all samples. Of the resulting ratios, the median value within each sample becomes the normalization factor for that sample, by which raw counts are divided to produce the normalized counts (Love et al., 2014). 
FFA in transition dairy cows is often associated with hepatic lipidosis (Gerloff, 2000), and it is possible that measured differences in miR-885 may stem from altered hepatic function. Suppression of this miRNA has inhibited proliferation of colorectal cancer cells $(\mathrm{Su}$ et al., 2018), but function in the context of the early-lactation mammary gland is yet unexplored.

Time of Colostrum Collection. Brix values of colostrum were not affected by time elapsed between parturition and colostrum collection $(P=0.51)$. We analyzed mapped miRNA for differences due to collection time and detected 5 DE miRNA according to Oasis, 2 of which were also DE according to miRDeep2 (Figure 6). Of those, 4 (miR-10b, miR-3431, miR-127, and miR-184) became more abundant as collection time was delayed, and 1 (miR-2284x) decreased in abundance over time. Others have observed differences in miRNA profile between lactation stages (Chen et al., 2010; Sun et al., 2013; Do et al., 2017); the differences we observed may be associated with changes in mammary gland activity between late gestation, lactogenesis, and galactopoiesis.

\section{Potential Effects of miRNA Abundant in Colostrum}

Although we detected few DE miRNA associated with adiposity, the miRNA highly abundant in colostrum also provide valuable data for their potential regulatory effects on the dam as well as on the neonate. Figure 2 shows the most abundantly expressed miRNA, using the normalized count data produced by DESeq2, averaged across samples. Supplemental data (File S1; https://doi.org/10.3168/jds.2019-16675) contains a complete list of detected miRNA. The 10 most abundant miRNA, according to miRDeep2 mapping, were miR-30a, miR-148a, let-7a, miR-181a, let-7f, miR-26a, miR-22, miR-92a, miR-21, and miR-30d; collectively, these accounted for $71 \pm 1.4 \%( \pm \mathrm{SD})$ of miRNA reads. The most abundant known miRNA detected by Oasis aligned closely with miRDeep2 mapping results (Figure 2) and also largely aligned with the results of other studies (Alsaweed et al., 2016; Li et al., 2016; Do et al., 2017). Other studies have used functional analysis programs to predict functional pathways that are affected by the most abundant miRNA. Results commonly include broad pathways related to cell function, physiological system development, macromolecule metabolism, and immune response and cell trafficking. One reason that so many biological processes are potentially influenced is that one miRNA may bind to many different mRNA transcripts; for example, TargetScan.org (Agarwal et al., 2015) lists 1,466 different predicted target genes for the bovine miR-30-5p family. Although this highlights the broad scope of biological processes that could potentially be affected by miRNA regulation, it does little to narrow down which of these biological processes might be most relevant for a given physiological scenario. We therefore took the approach of exploring the most abundant miRNA in the context of their potential relevance for the newly-lactating dairy cow, or for the newborn calf exposed to miRNA through colostrum ingestion.

Lipid Metabolism. Mammary miRNA have been associated with fatty acid and lipid metabolism (Zhang et al., 2016; Tang et al., 2017; Chu et al., 2018). One obvious application involves milk fat synthesis; in addition to miR-221 and miR-29, miR-181a was plentiful in our colostrum samples and has been shown to regulate lipogenesis (Lian et al., 2016; Du et al., 2017). Lian et al. (2016) transfected primary bovine epithelial cells in vitro with a mir-181a mimic and observed downregulation of an acyl-CoA synthetase (ACSL1) and decreased intracellular lipid concentration. In contrast, in primary bovine hepatocytes, a miR-181a mimic induced an in-
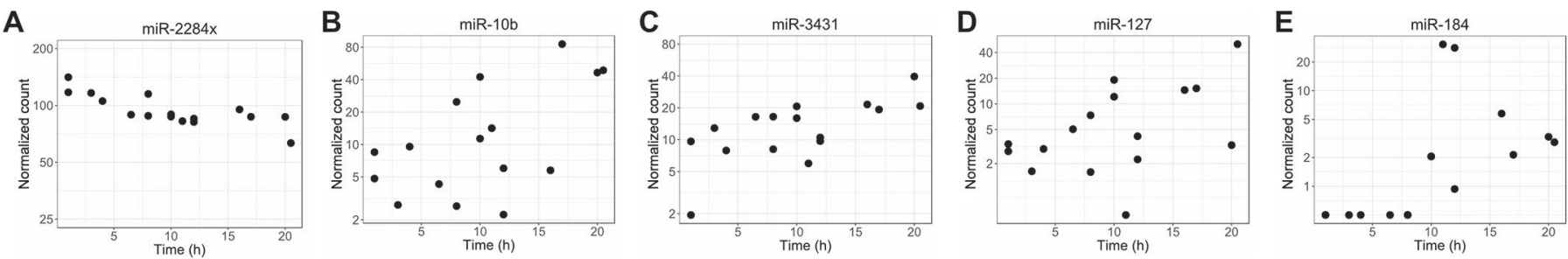

Figure 6. Changes in colostrum microRNA (miRNA) abundance associated with time elapsed before milking. Colostrum samples were collected from the initial milking following parturition of 16 multiparous Holstein cows. RNA was isolated from colostrum, sequenced, and analyzed for differences due to time elapsed between parturition and sample collection. Oasis 2.0 (https://oasis.dzne.de/) identified 5 differentially expressed (DE) miRNA: miR-2284x (A; fold change $-0.04 / \mathrm{h}$ ), miR-10b (B; fold change 0.18/h), miR-3431 (C; fold change 0.09/h), miR-127 (D; fold change $0.18 / \mathrm{h}$ ), and miR-184 [E; fold change $0.37 / \mathrm{h}$; false discovery rate (FDR) $P=0.09$ for all miRNA], which are shown as normalized counts by collection time. Normalized counts are calculated by DESeq2 (Love et al., 2014) by first dividing raw counts for each gene by the geometric mean of that gene across all samples. Of the resulting ratios, the median value within each sample becomes the normalization factor for that sample, by which raw counts are divided to produce the normalized counts (Love et al., 2014). In contrast to results of Oasis 2.0, miRDeep2 (https://www.mdc-berlin.de/content/mirdeep2-documentation) mapping identified only miR-10b and miR-127 as DE miRNA (both FDR $P=0.07)$. 
crease in triglyceride content (Du et al., 2017). Alterations in lipid metabolism may translate to net effects that differ according to tissue type or other factors.

Lipid metabolism processes are also active in the newborn consuming milk, including the digestion and absorption of nutrients as well as adipose tissue development. For example, brown adipose tissue (BAT) that is plentiful at birth is steadily depleted in favor of white adipose tissue (Symonds, 2013). Chen et al. (2017) discussed some of the miRNA that regulate BAT development, including miR-26, -27, -30, -93, $-155,-182$, and -378 , which are relatively abundant in our colostrum data. For instance, although ACSL1 is a target of miR-181a in regulation of milk fat synthesis (Lian et al., 2016), ACSL1 is also required for oxidation of fatty acid substrate during BAT thermogenesis in mice (Steensels and Ersoy, 2019). Although these studies focused on mice, most of the miRNA discussed are broadly conserved across species (targetscan.org; Agarwal et al., 2015) and may have similar activity in the bovine. Consumption of colostrum at birth therefore may contribute to the activation of BAT thermogenesis and adipose tissue remodeling; however, the extent to which colostral miRNA contribute is unknown.

Immune Function. The greater abundance of immune-related miRNA in colostrum compared with mature milk has been described in multiple species (Izumi et al., 2012; Sun et al., 2013; Modepalli et al., 2014; Ma et al., 2017). Documentation linking specific milk miRNA to immune function has been described previously ( $\mathrm{Gu}$ et al., 2012; Ma et al., 2017), including for miR-148a, -92a, -30a, -30d, -25, -182, -191, -21, $-27 \mathrm{~b}$, and let-7a, which were all in the top 20 of our detected miRNA (Figure 2). Liang et al. (2015) provided a thorough review of the potential for miRNA to influence the development of the bovine mucosal immune system. In addition, at least miR-21 and miR29 (both within the top 10 in our data) can bind to endolysosomal toll-like receptors to instigate innate immune cytokine production (Fabbri et al., 2012; Young et al., 2017). In addition to potential neonatal effects, the miRNA present in the mammary gland may also contribute to mammary health. In vitro Staphylococcus aureus or Escherichia coli bacterial challenges to MEC resulted in altered miRNA expression, including upregulation of miR-148a, -92, and -21, and downregulation of let-7a and mir-423 (Jin et al., 2014), which were highly abundant in our colostrum samples. In primary MEC infected with Streptococcus uberis, mir-22a was among those downregulated and predicted to be involved in pathways related to innate immune response (Lawless et al., 2013). Naeem et al. (2012) reported a downregulation of miR-181a with S. uberis infection of mammary tissue, suggesting a role in regulation of proinflammatory genes. Although in our study none of these miRNA were DE, their presence may allow for a role in regulation of mammary health.

Cellular Differentiation and Development. MicroRNA that regulate cellular differentiation may have implications for the mammary gland adapting to the onset of lactation as well as for the neonate. In the mammary gland, survival of mammary alveolar progenitor cells has been altered by knockdown of specific miRNA in vitro (Elsarraj et al., 2013), and the same miRNA has been detected in human milk but not in plasma (Kosaka et al., 2010), suggesting local origin. MicroRNA with regulatory activity within MEC may be actively exported from the cell into milk or may escape via leakage of cell membranes (Chen et al., 2012b). In our data, miR-30a was the most abundantly expressed miRNA in colostrum, and together with the other 5 members of the miR-30 family (miR-30b, $-30 \mathrm{c},-30 \mathrm{~d},-30 \mathrm{e}$, and $-30 \mathrm{f}$ ), made up $35 \%$ of all mapped miRNA reads. Overexpression of miR-30b in the mammary tissue of transgenic mice reduced alveolar size and altered lipid droplet characteristics, resulting in impaired growth of offspring (Le Guillou et al., 2012).

The let-7 family was highly present in colostrum: let$7 \mathrm{a},-7 \mathrm{~b},-7 \mathrm{c},-7 \mathrm{~d},-7 \mathrm{e},-7 \mathrm{f},-7 \mathrm{~g},-7 \mathrm{i}$, and miR-98 together accounted for $15 \%$ of all mapped miRNA reads. This miRNA family is highly conserved across species and regulates cell differentiation (Lee et al., 2016). In a transgenic mouse model, let-7 overexpression decreased animal growth rates and altered glucose metabolism (Zhu et al., 2011). Data from both cell and lipid fractions of human milk showed similar abundance of let-7 family miRNA (Alsaweed et al., 2016), and mammary tissue isolated from both lactating and nonlactating cows showed abundant let-7a and $-7 \mathrm{f}$ across all samples (Wang et al., 2018). The presence of this miRNA family in milk may reflect involvement of miRNA regulation in maintenance of normal cell function in mammary tissue that is rapidly increasing metabolic activity and secretory capacity.

Some miRNA detected in our samples are thought to inhibit processes predominant at the onset of lactation. For instance, MiR-221 has recently been identified as a regulator of MEC proliferation and is downregulated at the onset of lactation (Jiao et al., 2019). Similarly, miR150 declines during lactogenesis, and forced expression resulted in an inhibition of MEC function (Heinz et al., 2016). Others, such as miR-29, are upregulated with the onset of milk production (Do et al., 2017). In cultured primary bovine MEC, siRNA knockdown of miR-29 impaired synthesis of casein, lactose, and triglycerides, and increased methylation of DNA near lactation-related genes (Bian et al., 2015), indicating an epigenetic role in milk synthesis. The second most 
abundant miRNA detected in our data, MiR-148, likewise targets DNA methyl transferases that add methyl groups to DNA (Duursma et al., 2008), which could have important implications either for programming of the mammary gland for the ensuing lactation or for development of the neonate.

MicroRNA in colostrum may also regulate neonate tissue development. Evidence indicates that exosomes containing miRNA can be taken up by rat intestinal epithelial cells, human colon carcinoma (Caco-2) cells (Wolf et al., 2015), and human macrophages (Izumi et al., 2015; Lässer et al., 2011); the enclosed miRNA may then regulate mRNA turnover and translation within the cell. Additionally, miRNA cargo taken up from the gut lumen may be released into circulation. Incubation of Caco-2 monolayers with bovine milk exosomes on the apical side resulted in the release of miR-29b and miR-200c on the basolateral side (Wolf et al., 2015). In this manner, miRNA ingested by the calf via colostrum may have local effects on intestinal epithelial tissue function as well as systemic effects. Using both human intestinal epithelial cells and Caco-2 cells, Peck et al. (2016) showed that miR-30 regulates differentiation and proliferation by modulating the activity of SOX9, a transcription factor that regulates intestinal epithelial cell proliferation and differentiation (Gracz and Magness, 2011). Liang et al. (2014) identified other miRNA that appeared to be important regulators of GI tissue development in neonatal dairy calves.

The general importance of miRNA signaling in GI maintenance and function was demonstrated through a Dicer knockout mouse model (Liu et al., 2016). Dicer is an RNase enzyme involved in miRNA biogenesis (Ha and Kim, 2014), processing cytoplasmic pre-miRNA to form an effector complex which binds to mRNA transcript targets to facilitate silencing. Elimination of Dicer activity inhibited all miRNA regulation of transcription in the GI tract, resulting in altered gut microbe populations and compromised barrier function of the colon (Liu et al., 2016).

MicroRNA Processing. Lastly, to reiterate the complexity of miRNA signaling and the challenges of data interpretation, let-7 and miR-103, both highly abundant in our samples, have demonstrated Dicer targeting (Tokumaru et al., 2008; Martello et al., 2010; Chaulk et al., 2014). A downregulation in Dicer production could affect a global and indiscriminatory reduction in miRNA processing and regulatory activity by miRNA. The abundance of miR-103 in milk samples collected by Do et al. (2017) was similar to our data and did not appear to be DE by stage of lactation. The importance of either of these miRNA in regulation of global miRNA processing in early lactation mammary function is unknown.

\section{CONCLUSIONS}

We hypothesized that cows with higher BCS would exhibit altered miRNA profiles in secreted colostrum compared with cows with more moderate BCS. This hypothesis was based on the immune suppression especially seen in overconditioned cows, combined with the anticipated role that microRNA play in regulation of immune cell signaling. Results failed to demonstrate broad effects, except that miR-486 was downregulated in colostrum of overconditioned cows and miR-885 was downregulated for cows with elevated circulating FFA. Mapping of raw sequencing data using both miRDeep2 and Oasis 2.0 resulted in similar statistical results. Overall, we found little evidence of broad differences in colostrum miRNA in cows of high compared with moderate BCS, but we documented the presence of numerous miRNA in colostrum, with potential importance for both the lactating cow and the neonate.

\section{ACKNOWLEDGMENTS}

This project was supported by the USDA Agriculture and Food Research Initiative, National Institute of Food and Agriculture (AFRI-NIFA, Washington, DC) Fellows Program, grant \#2017-67011-26044, as well as by NIFA Hatch Project 1018048. Bioanalyzer analyses were performed at the Molecular Biology Core at Kansas State University (Manhattan), which is supported by the Kansas State University College of Veterinary Medicine. Sequence data sets were generated by the University of Kansas Medical Center Genomics Core, which is supported by the University of Kansas School of Medicine (Kansas City), the Kansas Intellectual and Developmental Disability Research Center [National Institutes of Health (NIH) U54 HD090216; Kansas City], and the NIH Center of Biomedical Research Excellence (COBRE, Kansas City) Molecular Regulation of Cell Development and Differentiation (5P20GM104936-10). Bioinformatic analysis of sequencing data was performed on the Beocat Research Cluster at Kansas State University, which is funded in part by National Science Foundation (Alexandria, VA) grants CNS-1006860, EPS-1006860, and EPS-0919443.

\section{REFERENCES}

Agarwal, V., G. W. Bell, J.-W. Nam, and D. P. Bartel. 2015. Predicting effective microRNA target sites in mammalian mRNAs. eLife 4:e05005. https://doi.org/10.7554/eLife.05005.

Alsaweed, M., C. T. Lai, P. E. Hartmann, D. T. Geddes, and F. Kakulas. 2016. Human milk cells and lipids conserve numerous known and novel miRNAs, some of which are differentially expressed during lactation. PLoS One 11:e0152610. https://doi.org/10.1371/ journal.pone.0152610. 
Arntz, O. J., B. C. H. Pieters, M. C. Oliveira, M. G. A. Broeren, M. B. Bennink, M. de Vries, P. L. E. M. van Lent, M. I. Koenders, W. B. van den Berg, P. M. van der Kraan, and F. A. J. van de Loo. 2015. Oral administration of bovine milk derived extracellular vesicles attenuates arthritis in two mouse models. Mol. Nutr. Food Res. 59:1701-1712. https://doi.org/10.1002/mnfr.201500222.

Benmoussa, A., C. H. C. Lee, B. Laffont, P. Savard, J. Laugier, E. Boilard, C. Gilbert, I. Fliss, and P. Provost. 2016. Commercial dairy cow milk microRNAs resist digestion under simulated gastrointestinal tract conditions. J. Nutr. 146:2206-2215. https://doi org/10.3945/jn.116.237651.

Benmoussa, A., S. Ly, S. T. Shan, J. Laugier, E. Boilard, C. Gilbert, and P. Provost. 2017. A subset of extracellular vesicles carries the bulk of microRNAs in commercial dairy cow's milk. J. Extracell. Vesicles 6. https://doi.org/10.1080/20013078.2017.1401897.

Bian, Y., Y. Lei, C. Wang, J. Wang, L. Wang, L. Liu, L. Liu, X. Gao, and Q. Li. 2015. Epigenetic regulation of miR-29s affects the lactation activity of dairy cow mammary epithelial cells. J. Cell. Physiol. 230:2152-2163. https://doi.org/10.1002/jcp.24944.

Bielmann, V., J. Gillan, N. R. Perkins, A. L. Skidmore, S. Godden, and K. E. Leslie. 2010. An evaluation of Brix refractometry instruments for measurement of colostrum quality in dairy cattle. J. Dairy Sci. 93:3713-3721. https://doi.org/10.3168/jds.2009-2943.

Blans, K., M. S. Hansen, L. V. Sørensen, M. L. Hvam, K. A. Howard, and A. Möller. 2017. Pellet-free isolation of human and bovine milk extracellular vesicles by size-exclusion chromatography. J. Extracell. Vesicles 6:1294340. https://doi.org/10.1080/20013078 .2017 .1294340

Chaulk, S. G., V. J. Lattanzi, S. E. Hiemer, R. P. Fahlman, and X. Varelas. 2014. The Hippo pathway effectors TAZ/YAP regulate dicer expression and microRNA biogenesis through Let-7. J. Biol. Chem. 289:1886-1891. https://doi.org/10.1074/jbc.C113.529362.

Chen, C.-C., D. B. Stairs, R. B. Boxer, G. K. Belka, N. D. Horseman, J. V. Alvarez, and L. A. Chodosh. 2012a. Autocrine prolactin induced by the Pten-Akt pathway is required for lactation initiation and provides a direct link between the Akt and Stat5 pathways. Genes Dev. 26:2154-2168. https://doi.org/10.1101/gad .197343 .112

Chen, T., Q.-Y. Xi, R.-S. Ye, X. Cheng, Q.-E. Qi, S.-B. Wang, G. Shu, L.-N. Wang, X.-T. Zhu, Q.-Y. Jiang, and Y.-L. Zhang. 2014. Exploration of microRNAs in porcine milk exosomes. BMC Genomics 15:100. https://doi.org/10.1186/1471-2164-15-100.

Chen, X., C. Gao, H. Li, L. Huang, Q. Sun, Y. Dong, C. Tian, and S. Gao. 2010. Identification and characterization of microRNAs in raw milk during different periods of lactation, commercial fluid, and powdered milk products. Cell Res. 20:1128-1137. https://doi .org/10.1038/cr.2010.80.

Chen, X., H. Liang, J. Zhang, K. Zen, and C.-Y. Zhang. 2012b. Secreted microRNAs: A new form of intercellular communication. Trends Cell Biol. 22:125-132. https://doi.org/10.1016/j.tcb.2011 .12 .001 .

Chen, Y., R. Pan, and A. Pfeifer. 2017. Regulation of brown and beige fat by microRNAs. Pharmacol. Ther. 170:1-7. https://doi.org/10 .1016/j.pharmthera.2016.10.004.

Chu, M., Y. Zhao, S. Yu, Y. Hao, P. Zhang, Y. Feng, H. Zhang, D. Ma, J. Liu, M. Cheng, L. Li, W. Shen, H. Cao, Q. Li, and L. Min. 2018. miR-15b negatively correlates with lipid metabolism in mammary epithelial cells. Am. J. Physiol. Cell Physiol. 314:C43-C52. https:/ /doi.org/10.1152/ajpcell.00115.2017.

Cui, X., L. You, L. Zhu, X. Wang, Y. Zhou, Y. Li, J. Wen, Y. Xia, X. Wang, C. Ji, and X. Guo. 2018. Change in circulating microRNA profile of obese children indicates future risk of adult diabetes. Metabolism 78:95-105. https://doi.org/10.1016/j.metabol.2017.09 .006 .

de Candia, P., G. Spinetti, C. Specchia, E. Sangalli, L. La Sala, A. Uccellatore, S. Lupini, S. Genovese, G. Matarese, and A. Ceriello. 2017. A unique plasma microRNA profile defines type 2 diabetes progression. PLoS One 12:e0188980. https://doi.org/10.1371/ journal.pone.0188980.

Do, D. N., R. Li, P.-L. Dudemaine, and E. M. Ibeagha-Awemu. 2017. MicroRNA roles in signalling during lactation: An insight from differential expression, time course and pathway analyses of deep sequence data. Sci. Rep. 7:44605. https://doi.org/10.1038/ srep44605.

Dobin, A., C. A. Davis, F. Schlesinger, J. Drenkow, C. Zaleski, S. Jha, P. Batut, M. Chaisson, and T. R. Gingeras. 2013. STAR: Ultrafast universal RNA-seq aligner. Bioinformatics 29:15-21. https://doi .org/10.1093/bioinformatics/bts635.

Du, X., Y. Yang, C. Xu, Z. Peng, M. Zhang, L. Lei, W. Gao, Y. Dong, Z. Shi, X. Sun, Z. Wang, X. Li, X. Li, and G. Liu. 2017. Upregulation of miR-181a impairs hepatic glucose and lipid homeostasis. Oncotarget 8:91362-91378. https://doi.org/10.18632/oncotarget .20523 .

Duursma, A. M., M. Kedde, M. Schrier, C. L. E. Sage, and R. Agami. 2008. miR-148 targets human DNMT3b protein coding region. RNA 14:872-877. https://doi.org/10.1261/rna.972008.

Elsarraj, H. S., Y. Hong, K. Valdez, M. Carletti, S. M. Salah, M. Raimo, D. Taverna, P. Prochasson, U. Bharadwaj, D. J. Tweardy, L. K. Christenson, and F. Behbod. 2013. A novel role of microRNA146b in promoting mammary alveolar progenitor cell maintenance. J. Cell Sci. 126:2446-2458. https://doi.org/10.1242/jcs .119214.

Fabbri, M., A. Paone, F. Calore, R. Galli, E. Gaudio, R. Santhanam, F. Lovat, P. Fadda, C. Mao, G. J. Nuovo, N. Zanesi, M. Crawford, G. H. Ozer, D. Wernicke, H. Alder, M. A. Caligiuri, P. NanaSinkam, D. Perrotti, and C. M. Croce. 2012. MicroRNAs bind to Toll-like receptors to induce prometastatic inflammatory response. Proc. Natl. Acad. Sci. USA 109:E2110-E2116. https://doi.org/10 .1073/pnas.1209414109.

Ferguson, J. D., D. T. Galligan, and N. Thomsen. 1994. Principal descriptors of body condition score in Holstein cows. J. Dairy Sci. 77:2695-2703. https://doi.org/10.3168/jds.S0022-0302(94)77212 $-\mathrm{X}$.

Friedländer, M. R., S. D. Mackowiak, N. Li, W. Chen, and N. Rajewsky. 2012. miRDeep2 accurately identifies known and hundreds of novel microRNA genes in seven animal clades. Nucleic Acids Res. 40:37-52. https://doi.org/10.1093/nar/gkr688.

Gerloff, B. J. 2000. Dry cow management for the prevention of ketosis and fatty liver in dairy cows. Vet. Clin. North Am. Food Anim. Pract. 16:283-292. https://doi.org/10.1016/S0749-0720(15)30106 -7 .

Gracz, A. D., and S. T. Magness. 2011. Sry-box (SOX) transcription factors in gastrointestinal physiology and disease. Am. J. Physiol. Gastrointest. Liver Physiol. 300:G503-G515. https://doi.org/10 .1152/ajpgi.00489.2010.

Gu, Y., M. Li, T. Wang, Y. Liang, Z. Zhong, X. Wang, Q. Zhou, L. Chen, Q. Lang, Z. He, X. Chen, J. Gong, X. Gao, X. Li, and X. Lv. 2012. Lactation-related microRNA expression profiles of porcine breast milk exosomes. PLoS One 7:e43691. https://doi.org/10 1371/journal.pone.0043691.

Gui, J., Y. Tian, X. Wen, W. Zhang, P. Zhang, J. Gao, W. Run, L. Tian, X. Jia, and Y. Gao. 2011. Serum microRNA characterization identifies miR-885-5p as a potential marker for detecting liver pathologies. Clin. Sci. (Lond.) 120:183-193. https://doi.org/10.1042/ CS20100297.

Ha, M., and V. N. Kim. 2014. Regulation of microRNA biogenesis. Nat. Rev. Mol. Cell Biol. 15:509-524. https://doi.org/10.1038/ nrm3838.

Hagiwara, K., M. Domi, and J. Ando. 2008. Bovine colostral CD8positive cells are potent IFN-g-producing cells. Vet. Immunol. Immunopathol. 124:93-98. https://doi.org/10.1016/j.vetimm.2008.02 .018 .

Heinz, R. E., M. C. Rudolph, P. Ramanathan, N. S. Spoelstra, K. T. Butterfield, P. G. Webb, B. L. Babbs, H. Gao, S. Chen, M. A. Gordon, S. M. Anderson, M. C. Neville, H. Gu, and J. K. Richer. 2016. Constitutive expression of microRNA-150 in mammary epithelium suppresses secretory activation and impairs de novo lipogenesis. Development 143:4236-4248. https://doi.org/10.1242/dev.139642.

Ingvartsen, K. L., and K. M. Moyes. 2015. Factors contributing to immunosuppression in the dairy cow during the periparturient period. Jpn. J. Vet. Res. 63:S15-S24. https://doi.org/10.14943/jjvr .63.suppl.s15. 
Izumi, H., N. Kosaka, T. Shimizu, K. Sekine, T. Ochiya, and M. Takase. 2012. Bovine milk contains microRNA and messenger RNA that are stable under degradative conditions. J. Dairy Sci. 95:4831-4841. https://doi.org/10.3168/jds.2012-5489.

Izumi, H., M. Tsuda, Y. Sato, N. Kosaka, T. Ochiya, H. Iwamoto, K. Namba, and Y. Takeda. 2015. Bovine milk exosomes contain microRNA and mRNA and are taken up by human macrophages. J. Dairy Sci. 98:2920-2933. https://doi.org/10.3168/jds.2014-9076.

Jiao, B. L., X. L. Zhang, S. H. Wang, L. X. Wang, Z. X. Luo, H. B. Zhao, H. Khatib, and X. Wang. 2019. MicroRNA-221 regulates proliferation of bovine mammary gland epithelial cells by targeting the STAT5a and IRS1 genes. J. Dairy Sci. 102:426-435. https:// doi.org/10.3168/jds.2018-15108

Jin, W., E. M. Ibeagha-Awemu, G. Liang, F. Beaudoin, X. Zhao, and L. L. Guan. 2014. Transcriptome microRNA profiling of bovine mammary epithelial cells challenged with Escherichia coli or Staphylococcus aureus bacteria reveals pathogen directed microRNA expression profiles. BMC Genomics 15:181. https://doi.org/10 $.1186 / 1471-2164-15-181$

Karolina, D. S., S. Tavintharan, A. Armugam, S. Sepramaniam, S. L. T. Pek, M. T. K. Wong, S. C. Lim, C. F. Sum, and K. Jeyaseelan. 2012. Circulating miRNA profiles in patients with metabolic syndrome. J. Clin. Endocrinol. Metab. 97:E2271-E2276. https://doi .org/10.1210/jc.2012-1996.

Kosaka, N., H. Izumi, K. Sekine, and T. Ochiya. 2010. microRNA as a new immune-regulatory agent in breast milk. Silence 1:7. https:// doi.org/10.1186/1758-907X-1-7.

Kozomara, A., and S. Griffiths-Jones. 2014. miRBase: Annotating high confidence microRNAs using deep sequencing data. Nucleic Acids Res. 42:D68-D73. https://doi.org/10.1093/nar/gkt1181.

Kusuma, R. J., S. Manca, T. Friemel, S. Sukreet, C. Nguyen, and J. Zempleni. 2016. Human vascular endothelial cells transport foreign exosomes from cow's milk by endocytosis. Am. J. Physiol. Cell Physiol. 310:C800-C807. https://doi.org/10.1152/ajpcell.00169 .2015 .

Lacetera, N., D. Scalia, U. Bernabucci, B. Ronchi, D. Pirazzi, and A. Nardone. 2005. Lymphocyte functions in overconditioned cows around parturition. J. Dairy Sci. 88:2010-2016. https://doi.org/10 .3168/jds.S0022-0302(05)72877-0.

Langel, S. N., W. A. Wark, S. N. Garst, R. E. James, M. L. McGilliard, C. S. Petersson-Wolfe, and I. Kanevsky-Mullarky. 2015. Effect of feeding whole compared with cell-free colostrum on calf immune status: The neonatal period. J. Dairy Sci. 98:3729-3740. https://doi.org/10.3168/jds.2014-8422.

Langmead, B., C. Trapnell, M. Pop, and S. L. Salzberg. 2009. Ultrafast and memory-efficient alignment of short DNA sequences to the human genome. Genome Biol. 10. https://doi.org/10.1186/gb $-2009-10-3-\mathrm{r} 25$.

Lässer, C., V. S. Alikhani, K. Ekström, M. Eldh, P. T. Paredes, A Bossios, M. Sjöstrand, S. Gabrielsson, J. Lötvall, and H. Valadi. 2011. Human saliva, plasma and breast milk exosomes contain RNA: Uptake by macrophages. J. Transl. Med. 9:9. https://doi .org/10.1186/1479-5876-9-9.

Lawless, N., A. B. K. Foroushani, M. S. Mccabe, C. O. Farrelly, and D. J. Lynn. 2013. Next generation sequencing reveals the expression of a unique miRNA profile in response to a gram-positive bacterial infection. PLoS One 8:e57543. https://doi.org/10.1371/journal .pone.0057543.

Le Guillou, S., N. Sdassi, J. Laubier, B. Passet, M. Vilotte, J. Castille, D. Laloë, J. Polyte, S. Bouet, F. Jaffrézic, E. P. Cribiu, J. L. Vilotte, and F. Le Provost. 2012. Overexpression of miR-30b in the developing mouse mammary gland causes a lactation defect and delays involution. PLoS One 7:e45727. https://doi.org/10.1371/ journal.pone.0045727.

Lee, H., S. Han, C. S. Kwon, and D. Lee. 2016. Biogenesis and regulation of the let-7 miRNAs and their functional implications. Protein Cell 7:100-113. https://doi.org/10.1007/s13238-015-0212-y.

Li, D., X. Xie, J. Wang, Y. Bian, Q. Li, X. Gao, and C. Wang. 2015a. MiR-486 regulates lactation and targets the PTEN gene in cow mammary glands. PLoS One 10:e0118284. https://doi.org/10 .1371/journal.pone.0118284
Li, R., F. Beaudoin, A. A. Ammah, N. Bissonnette, C. Benchaar, X. Zhao, C. Lei, and E. M. Ibeagha-Awemu. 2015b. Deep sequencing shows microRNA involvement in bovine mammary gland adaptation to diets supplemented with linseed oil or safflower oil. BMC Genomics 16:884. https://doi.org/10.1186/s12864-015-1965-7.

Li, R., P.-L. Dudemaine, X. Zhao, C. Lei, and E. M. Ibeagha-Awemu. 2016. Comparative analysis of the miRNome of bovine milk fat, whey and cells. PLoS One 11:e0154129. https://doi.org/10.1371/ journal.pone.0154129.

Li, Y., Z. Zhang, F. Liu, W. Vongsangnak, Q. Jing, and B. Shen. 2012. Performance comparison and evaluation of software tools for microRNA deep-sequencing data analysis. Nucleic Acids Res. 40:4298-4305. https://doi.org/10.1093/nar/gks043.

Lian, S., J. R. Guo, X. M. Nan, L. Ma, J. J. Loor, and D. P. Bu. 2016. MicroRNA Bta-miR-181a regulates the biosynthesis of bovine milk fat by targeting ACSL1. J. Dairy Sci. 99:3916-3924. https://doi .org/10.3168/jds.2015-10484.

Liang, G., N. Malmuthuge, L. L. Guan, and P. Griebel. 2015. Mode systems to analyze the role of miRNAs and commensal microflora in bovine mucosal immune system development. Mol. Immunol. 66:57-67. https://doi.org/10.1016/j.molimm.2014.10.014.

Liang, G., N. Malmuthuge, T. B. McFadden, H. Bao, P. J. Griebel, P. Stothard, and L. L. Guan. 2014. Potential regulatory role of microRNAs in the development of bovine gastrointestinal tract during early life. PLoS One 9:e92592. https://doi.org/10.1371/ journal.pone.0092592.

Liu, S., A. P. da Cunha, R. M. Rezende, R. Cialic, Z. Wei, L. Bry, L. E. Comstock, R. Gandhi, and H. L. Weiner. 2016. The host shapes the gut microbiota via fecal microRNA. Cell Host Microbe 19:32-43. https://doi.org/10.1016/j.chom.2015.12.005.

Love, M. I., W. Huber, and S. Anders. 2014. Moderated estimation of fold change and dispersion for RNA-seq data with DESeq2. Genome Biol. 15:550. https://doi.org/10.1186/s13059-014-0550-8.

Ma, J., C. Wang, K. Long, H. Zhang, J. Zhang, L. Jin, Q. Tang, A. Jiang, X. Wang, S. Tian, L. Chen, D. He, D. Li, S. Huang, Z. Jiang, and M. Li. 2017. Exosomal microRNAs in giant panda (Ailuropoda melanoleuca) breast milk: Potential maternal regulators for the development of newborn cubs. Sci. Rep. 7:3507. https://doi.org/ 10.1038/s41598-017-03707-8.

Manning, P., P. E. Munasinghe, J. B. Papannarao, A. R. Gray, W Sutherland, and R. Katare. 2019. Acute weight loss restores dysregulated circulating microRNAs in individuals who are obese. J. Clin. Endocrinol. Metab. 104:1239-1248. https://doi.org/10.1210/ jc.2018-00684.

Martello, G., A. Rosato, F. Ferrari, A. Manfrin, M. Cordenonsi, S. Dupont, E. Enzo, V. Guzzardo, M. Rondina, T. Spruce, A. R. Parenti, M. G. Daidone, S. Bicciato, and S. Piccolo. 2010. A microRNA targeting Dicer for metastasis control. Cell 141:1195-1207. https:/ /doi.org/10.1016/j.cell.2010.05.017.

Modepalli, V., A. Kumar, L. A. Hinds, J. A. Sharp, K. R. Nicholas, and C. Lefevre. 2014. Differential temporal expression of milk miRNA during the lactation cycle of the marsupial tammar wallaby (Macropus eugenii). BMC Genomics 15:1012. https://doi.org/ 10.1186/1471-2164-15-1012.

Naeem, A., K. Zhong, S. J. Moisá, J. K. Drackley, K. M. Moyes, and J. J. Loor. 2012. Bioinformatics analysis of microRNA and putative target genes in bovine mammary tissue infected with Streptococcus uberis. J. Dairy Sci. 95:6397-6408. https://doi.org/10.3168/ jds.2011-5173.

Palin, M.-F., C. Farmer, and C. R. A. Duarte. 2017. Adipokines affect mammary growth and function in farm animals. J. Anim. Sci 95:5689. https://doi.org/10.2527/jas2017.1777.

Peck, B. C. E., J. Sincavage, S. Feinstein, A. T. Mah, J. G. Simmons, P. K. Lund, and P. Sethupathy. 2016. miR-30 family controls proliferation and differentiation of intestinal epithelial cell models by directing a broad gene expression program that includes SOX9 and the ubiquitin ligase pathway. J. Biol. Chem. 291:15975-15984. https://doi.org/10.1074/jbc.M116.733733.

Rahman, R.-U., A. Gautam, J. Bethune, A. Sattar, M. Fiosins, D. S. Magruder, V. Capece, O. Shomroni, and S. Bonn. 2018. Oasis 2: 
Improved online analysis of small RNA-seq data. BMC Bioinformatics 19:54 https://doi.org/10.1186/s12859-018-2047-z.

Raitoharju, E., I. Seppälä, L.-P. Lyytikäinen, J. Viikari, M. Ala-Korpela, P. Soininen, A. J. Kangas, M. Waldenberger, N. Klopp, T. Illig, J. Leiviskä, B.-M. Loo, N. Oksala, M. Kähönen, N. HutriKähönen, R. Laaksonen, O. Raitakari, and T. Lehtimäki. 2016. Blood hsa-miR-122-5p and hsa-miR-885-5p levels associate with fatty liver and related lipoprotein metabolism-The Young Finns Study. Sci. Rep. 6:38262. https://doi.org/10.1038/srep38262.

Rani, P., M. Vashisht, N. Golla, S. Shandilya, S. K. Onteru, and D. Singh. 2017. Milk miRNAs encapsulated in exosomes are stable to human digestion and permeable to intestinal barrier in vitro. J. Funct. Foods 34:431-439. https://doi.org/10.1016/j.jff.2017.05 .009 .

Samuel, M., D. Chisanga, M. Liem, S. Keerthikumar, S. Anand, C.S. Ang, C. G. Adda, E. Versteegen, M. Jois, and S. Mathivanan. 2017. Bovine milk-derived exosomes from colostrum are enriched with proteins implicated in immune response and growth. Sci. Rep. 7:5933. https://doi.org/10.1038/s41598-017-06288-8.

Sandrim, V. C., M. R. Luizon, A. C. Palei, J. E. Tanus-Santos, and R. C. Cavalli. 2016. Circulating microRNA expression profiles in pre-eclampsia: Evidence of increased miR-885-5p levels. BJOG. 123:2120-2128. https://doi.org/10.1111/1471-0528.13903.

Silva, L. F. P., M. J. VandeHaar, B. K. Whitlock, R. P. Radcliff, and H. A. Tucker. 2002. Short communication: Relationship between body growth and mammary development in dairy heifers. J. Dairy Sci. 85:2600-2602. https://doi.org/10.3168/jds.S0022 $-0302(02) 74344-0$.

Sordillo, L. M., G. A. Contreras, and S. L. Aitken. 2009. Metabolic factors affecting the inflammatory response of periparturient dairy cows. Anim. Health Res. Rev. 10:53-63. https://doi.org/10.1017/ S1466252309990016.

Sordillo, L. M., and W. Raphael. 2013. Significance of metabolic stress, lipid mobilization, and inflammation on transition cow disorders. Vet. Clin. North Am. Food Anim. Pract. 29:267-278. https://doi .org/10.1016/j.cvfa.2013.03.002.

Steensels, S., and B. A. Ersoy. 2019. Fatty acid activation in thermogenic adipose tissue. Biochim. Biophys. Acta Mol. Cell Biol. Lipids 1864:79-90. https://doi.org/10.1016/j.bbalip.2018.05.008.

Su, M., B. Qin, F. Liu, Y. Chen, and R. U. I. Zhang. 2018. miR-885-5p upregulation promotes colorectal cancer cell proliferation and migration by targeting suppressor of cytokine signaling. Oncol. Lett. 16:65-72. https://doi.org/10.3892/ol.2018.8645.

Sun, J., K. Aswath, S. G. Schroeder, J. D. Lippolis, T. A. Reinhardt, and T. S. Sonstegard. 2015. MicroRNA expression profiles of bovine milk exosomes in response to Staphylococcus aureus infection. BMC Genomics 16:806. https://doi.org/10.1186/s12864-015-2044 -9 .

Sun, Q., X. Chen, J. Yu, K. Zen, C.-Y. Zhang, and L. Li. 2013. Immune modulatory function of abundant immune-related microRNAs in microvesicles from bovine colostrum. Protein Cell 4:197210. https://doi.org/10.1007/s13238-013-2119-9.

Symonds, M. E. 2013. Brown adipose tissue growth and development. Scientifica (Cairo) 2013. https://doi.org/10.1155/2013/305763.

Tang, K. Q., Y. N. Wang, L. S. Zan, and W. C. Yang. 2017. miR27a controls triacylglycerol synthesis in bovine mammary epithelial cells by targeting peroxisome proliferator-activated receptor gamma. J. Dairy Sci. 100:4102-4112. https://doi.org/10.3168/jds 2016-12264.

Tokumaru, S., M. Suzuki, H. Yamada, M. Nagino, and T. Takahashi. 2008. let-7 regulates Dicer expression and constitutes a negative feedback loop. Carcinogenesis 29:2073-2077. https://doi.org/10 $.1093 /$ carcin/bgn187.
Tremblay, M., M. Kammer, H. Lange, S. Plattner, C. Baumgartner, J. A. Stegeman, J. Duda, R. Mansfeld, and D. Döpfer. 2018. Identifying poor metabolic adaptation during early lactation in dairy cows using cluster analysis. J. Dairy Sci. 101:7311-7321. https:// doi.org/10.3168/jds.2017-13582.

Turchinovich, A., L. Weiz, and B. Burwinkel. 2012. Extracellular miRNAs: The mystery of their origin and function. Trends Biochem. Sci. 37:460-465. https://doi.org/10.1016/j.tibs.2012.08.003.

Vliegenthart, A. D. B., J. M. Shaffer, J. I. Clarke, L. E. J. Peeters, A. Caporali, D. N. Bateman, D. M. Wood, P. I. Dargan, D. G. Craig, J. K. Moore, A. I. Thompson, N. C. Henderson, D. J. Webb, J. Sharkey, D. J. Antoine, B. K. Park, M. A. Bailey, E. Lader, K. J. Simpson, and J. W. Dear. 2015. Comprehensive microRNA profiling in acetaminophen toxicity identifies novel circulating biomarkers for human liver and kidney injury. Scientific Reports. 5:15501. https://doi.org/10.1038/srep15501.

Wang, X., L. Zhang, J. Jin, A. Xia, C. Wang, Y. Cui, B. Qu, Q. Li, and C. Sheng. 2018. Comparative transcriptome analysis to investigate the potential role of miRNAs in milk protein/fat quality. Sci. Rep. 8:6250. https://doi.org/10.1038/s41598-018-24727-y.

Wang, Z., X. Hou, B. Qu, J. Wang, X. Gao, and Q. Li. 2014. Pten regulates development and lactation in the mammary glands of dairy cows. PLoS One 9:e102118. https://doi.org/10.1371/journal pone.0102118.

Wolf, T., S. R. Baier, and J. Zempleni. 2015. The intestinal transport of bovine milk exosomes is mediated by endocytosis in human colon carcinoma Caco-2 cells and rat small intestinal IEC-6 cells. J. Nutr. 145:2201-2206. https://doi.org/10.3945/jn.115.218586.

Young, N. A., G. R. Valiente, J. M. Hampton, L.-C. Wu, C. J. Burd, W. L. Willis, M. Bruss, H. Steigelman, M. Gotsatsenko, S. A. Amici, M. Severin, L. M. Claverie, M. Guerau-de-Arellano, A. Lovett-Racke, S. Ardoin, and W. N. Jarjour. 2017. Estrogen-regulated STAT1 activation promotes TLR8 expression to facilitate signaling via microRNA-21 in systemic lupus erythematosus. Clin. Immunol. 176:12-22. https://doi.org/10.1016/j.clim.2016.12.005.

Zhang, C., H. Wu, Y. Wang, S. Zhu, J. Liu, X. Fang, and H. Chen 2016. Circular RNA of cattle casein genes are highly expressed in bovine mammary gland. J. Dairy Sci. 99:4750-4760. https://doi .org/10.3168/jds.2015-10381.

Zhu, H., N. Shyh-Chang, A. Segre, G. Shinoda, S. P. Shah, W. S. Einhorn, A. Takeuchi, J. M. Engreitz, J. P. Hagan, M. G. Kharas, A. Urbach, J. E. Thornton, R. Triboulet, R. I. Gregory, D. Consortium, M. Investigators, D. Altshuler, and G. Q. Daley. 2011. The Lin28/let-7 axis regulates glucose metabolism. Cell 147:81-94. https://doi.org/10.1016/j.cell.2011.08.033.

Zwick, R. K., M. C. Rudolph, B. A. Shook, B. Holtrup, E. Roth, V. Lei, A. Van Keymeulen, V. Seewaldt, S. Kwei, J. Wysolmerski, M. S. Rodeheffer, and V. Horsley. 2018. Adipocyte hypertrophy and lipid dynamics underlie mammary gland remodeling after lactation. Nat. Commun. 9:3592. https://doi.org/10.1038/s41467-018 $-05911-0$.

\section{APPENDIX}

\section{Data Access}

Raw sequencing data files can be accessed at the National Center for Biotechnology Information (NCBI) Sequence Read Archive, under BioProject \#PRJNA528768. 